\title{
Status sociométrico de alunos com deficiência intelectual e com transtorno do espectro do autismo na educação infantil e ensino fundamental
}

Sociometric status of students with intellectual disabilities and autism spectrum disorder in early childhood education and elementary education

Status sociométrico de estudiantes con discapacidades intelectuales y trastorno del espectro autista en educación preescolar y educación primaria

\section{Cristiane Makida Dyonisio}

Professora mestra na Universidade Cidade de São Paulo, São Paulo, São Paulo, Brasil. cristiane.makida@gmail.com ORCID - https://orcid.org/0000-0002-5997-8818

\section{Roberto Gimenez}

Professor doutor na Universidade Cidade de São Paulo, São Paulo, São Paulo, Brasil. roberto.gimenez@unicid.edu.br ORCID - https://orcid.org/0000-0002-4953-5941

Recebido em 29 de janeiro de 2019

Aprovado em 5 de março de 2020

Publicado em 10 de abril de 2020

\section{RESUMO}

O presente estudo teve por objetivo comparar o status sociométrico de alunos com deficiência intelectual e com transtorno do espectro do autismo (TEA) nos âmbitos da Educação Infantil (EI) e do Ensino Fundamental (EF). Participaram deste estudo 51 indivíduos, dos quais 25 estavam matriculados na El e 26 no EF. O instrumento utilizado correspondeu à Sociometria, que possibilita identificar o nível de aceitação ou rejeição de indivíduos em situações de grupo. Para tanto, foi aplicado um teste sociométrico, com o intuito de indagar, a todos os educandos, sobre a preferência de escolhas em nível social, uma de caráter positivo (aceitação em relação ao grupo) e outra, negativo (rejeição em relação ao grupo). Todos foram submetidos ao teste, entretanto, foram analisados os resultados de duas crianças em cada nível da Educação Básica, totalizando 4 estudantesalvo: duas crianças com deficiência intelectual e outras duas diagnosticadas com TEA. A partir da aplicação do teste, foi possível identificar o status dos indivíduos em seu grupo social. Os resultados obtidos apontaram que os alunos-alvo da Educação Infantil apresentaram status de isolado e excluído. Em contrapartida, os alunos do Ensino Fundamental apresentaram um status sociométrico mais positivo, como o de não-excluído e popular. Conclui-se que o tempo de convívio entre os sujeitos é um fator determinante na criação de vínculo. Além disso, identificou-se que, mais do que a deficiência, a dimensão subjetiva parece ser um fator crucial no processo de interação.

Palavras-chave: Interação social; Educação Infantil; Ensino Fundamental. 
http://dx.doi.org/10.5902/1984686X36641

\section{ABSTRACT}

The present study aimed at comparing the sociometric status of students with intellectual disability and autism spectrum disorder (ASD) in the areas of Early Childhood Education (ECE) and Elementary Education (EE). Fifty-one children participated in this study, of which 25 were enrolled in ECE and 26 in EE. The instrument used corresponded to Sociometry, which made it possible to identify the acceptance or rejection of individuals in group situations. In order to do so, a sociometric test was applied aiming to inquiry all students about the preference for social level choices, one positive (acceptance in relation to the group) and another negative (rejection in relation to the group). All students were submitted to the test, however, only the results of two children at each level of Basic Education were analyzed, totaling 4 target- students: two children with intellectual disability and two diagnosed with ASD. Through the application of the test, it was possible to identify the status of individuals in their social group. The results indicated that the target-students of Early Childhood Education presented isolated and excluded status. On the other hand, the Elementary School students presented a more positive sociometric status, such as nonexcluded and popular. It is concluded that the time of coexistence between the subjects is a determining factor in the creation of bond. In addition, it was identified that more than disability, the subjective dimension seems to be a crucial factor in the interaction process.

Keywords: Social interaction; Early Childhood Education; Elementary Education.

\section{RESUMEN}

El objetivo del presente estudio fue comparar el estado sociométrico de los estudiantes con discapacidad intelectual y trastorno del espectro autista (TEA) en el ámbito de la educación de la primera infancia (IE) y la escuela primaria (EP). Cincuenta y un individuos participaron en este estudio, de los cuales 25 se inscribieron en IS y 26 en EF. El instrumento utilizado correspondió a Sociometría, que permite identificar el nivel de aceptación o rechazo de individuos en situaciones grupales. Con este fin, se aplicó una prueba sociométrica para preguntar a todos los estudiantes sobre la preferencia de las elecciones sociales, una positiva (aceptación en relación con el grupo) y la otra negativa (rechazo en relación con el grupo). Todos fueron sometidos a la prueba; sin embargo, se analizaron los resultados de dos niños en cada nivel de Educación Básica, totalizando 4 estudiantes objetivo: dos niños con discapacidad intelectual y otros dos diagnosticados con TEA. A partir de la aplicación de la prueba, fue posible identificar el estado de las personas en su grupo social. Los resultados mostraron que los estudiantes objetivo de jardín de infantes presentaban un estado aislado y excluido. Por el contrario, los estudiantes de primaria presentaron un estado sociométrico más positivo, como el no excluido y el popular. Se puede concluir que el tiempo que pasan juntos entre los sujetos es un factor determinante en la vinculación. Además, se identificó que, más que la discapacidad, la dimensión subjetiva parece ser un factor crucial en el proceso de interacción

Palabras clave: Interacción social; Educación Infantil; Enseñanza Fundamental.

\section{Introdução}

Abordar o tema inclusão e educação básica remete a discussões sobre sua implantação, sua validade e as barreiras para sua efetivação. Os diferentes agentes da instituição escolar envolvidos com os processos de aprendizagem, tais como 
coordenadores, professores e auxiliares de ensino, apresentam diversas dificuldades para modificar suas práticas (baseadas em métodos tradicionais e excludentes), almejando a inclusão de todos (ALMEIDA, 2012; MAKIDA-DYONISIO; MARTINS, GIMENEZ, 2016). Reconhecidamente, houve um aumento considerável de acesso de pessoas com deficiência na escola regular (INEP, 2012; 2018). Em 2012, o censo apontou 820,4 mil matrículas de crianças e jovens com necessidades especiais, constatando-se que $76 \%$ dos estudantes estavam em classes comuns. Em contrapartida, em 2018, foram matriculados 1.181 .276 estudantes e $86 \%$ estariam matriculados nestas mesmas classes. Diante de tal fato, pode ser considerado um desafio compreender os meios mais efetivos para o acolhimento dessas crianças (ALMEIDA, 2012; MAKIDA-DYONISIO; MARTINS; GIMENEZ, 2016).

Padilha e Oliveira (2013) definem a inclusão social como prerrogativa de todos os agentes da sociedade, com múltiplas facetas que podem ser analisadas ou compreendidas a partir de diversos pontos de vista. Para os mesmos autores, a escola corresponderia a um segmento que contribui para a constituição de uma sociedade inclusiva e que viabiliza a equidade entre os sujeitos, tanto nas interações humanas como no acesso à cultura e ao conhecimento científico, contribuindo para a formação de sujeitos mais autônomos e protagonistas. A partir deste prisma, a escola tem um papel de extrema relevância, uma vez que ela corresponderia ao primeiro espaço para o estabelecimento de vínculos sociais, fora do núcleo familiar.

Para seguir os indicativos de escola inclusiva, tal acolhimento não se limitaria a uma diminuição da distância física, ou seja, a colocar os alunos com deficiência no mesmo ambiente como uma mera execução de direitos (EDLER DE CARVALHO,1991; NEGRINI; COSTA; ORTIZ; FREITAS, 2010), mas dependeria fundamentalmente de uma ambiência ao seu processo de aprendizagem. Alguns estudos apontam que as interações sociais estabelecidas no ambiente escolar seriam imprescindíveis para sua inclusão no que tange à sua percepção de pertencimento e aceitação em relação ao grupo (GREENWAY, 2000; LACEY, 2001; GURALNICK, 2002; ORSMOND; KRAUSS; SELTEZER, 2004; BATISTA, ENUMO, 2004; BAYDIK; BAKKALOĞLU, 2009; ANHÃO; PFEIFER; SANTOS, 2010).

Desse modo, o estabelecimento de vínculos entre os indivíduos é uma prerrogativa para o processo inclusivo. Vale ressaltar que se entende como vínculo o modo que cada pessoa interage com os outros, em um tempo e espaço determinados. Além disso, este vínculo estaria diretamente relacionado com a noção de papel, de status e de comunicação, 
http://dx.doi.org/10.5902/1984686X36641

seja ela por meio da interação direta com o outro, seja por meio de elementos do ambiente culturalmente estruturado (PICHÓN-RIVIÉRE, 2007). A partir destes vínculos, seria possível internalizar os conceitos e significados, matéria-prima essencial para 0 desenvolvimento psicológico do indivíduo (OLIVEIRA,1997).

A Psicologia Social do Desenvolvimento tem apresentado alguns estudos acerca da importância da interação entre os sujeitos para a formação da personalidade (p.e. HARRIS, 1995; 1999). Para este autor, as questões de ordem cultural são fundamentais para a forma pela qual cada grupo estabelece estas interações e estipula sua forma de convívio por afinidade; elas embasariam os critérios utilizados pelos grupos para categorizar, classificar, nomear, rotular e dividir as pessoas.

Assim, ser membro de um grupo estaria relacionado à autocategorização, ou seja, às autoimagens que são assumidas, altamente variáveis e específicas para cada situação. Desta forma, as categorizações são dependentes do contexto social em que o indivíduo está inserido. Por exemplo: a categoria criança pode ser modificada e subdividida por gênero (feminino e masculino), faixa etária (mais novas, mais velhas), por raças ou etnias, etc. (TURNER, 1987).

Um ponto que merece reflexão diz respeito a qual imagem a criança faz de si própria, seja no âmbito individual ou em grupo (TURNER, 1987), além de como isso poderia depender do seu nível de desenvolvimento cognitivo. Tal fato faz com que sejam necessários estudos que avaliem como acontece esse processo de interação entre as crianças e os efetivos impactos sobre a construção da autoimagem das mesmas, em decorrência de diferentes graus de deficiência ou transtornos de desenvolvimento.

Silva (2000) levanta o conceito de identidade na formação dos grupos. Para o referido autor, as pessoas tendem à aproximação com outros indivíduos pela identificação por semelhança, sendo considerados "normais". Em contrapartida, aqueles que não apresentam as mesmas características das pessoas são considerados "estranhos", "anormais", prevalecendo a desvalorização do sujeito. As categorizações influenciam na identificação dos pares, intra e intergrupos. Desse modo, afiliar-se a grupos acarreta a reação "eles gostam de mim, gosto deles" (DALBOSCO, 2015; HARRIS, 1995; 1999).

Ao se levar em consideração o contexto da Educação Infantil, Batista e Enumo (2004) afirmam que, nos primeiros anos escolares, a tendência é de aproximação das crianças do mesmo sexo, idade ou raça. Por outro lado, a falta de interação com outras pessoas, pelos mais diversos motivos, pode acarretar distúrbios psicológicos na idade adulta (BOCK, 2007; 
ILYAS; SHAHED, 2020). Este fator é crucial, sobretudo ao se levar em consideração que se trata de um período importante para o desenvolvimento da personalidade e da aprendizagem da língua, por meio da imitação e por observação de pais, professores, irmãos ou pares (HARRIS,1999; 1995). Além da reprodução das ações dos outros, a imitação permite uma reconstrução própria daquilo que é observado, o que auxilia o desenvolvimento e o amadurecimento das ações humanas (OLIVEIRA, 1997).

Em especial, crianças com deficiência intelectual e TEA, abordadas nesse estudo, têm como peculiaridades a dificuldade na interação social em razão de dificuldades de estruturação das representações simbólicas (GONÇALVES et al., 2004). Em especial, esses autores entendem por representações simbólicas a forma pela qual cada indivíduo compreende cada contexto e interage nele. Para tanto, os mesmos se baseiam no referencial teórico de Vygotsky (1994), que parte do pressuposto de que as crianças não nascem aptas ao desempenho de papéis sociais, mas os desenvolvem por meio de um processo sóciohistórico a partir de suas experiências vividas de forma singular. A apropriação da cultura ocorreria a partir da interação social. Assim, para Vygotsky, o homem, como sujeito, se caracteriza como um ser simbólico, integrando realidades culturais e históricas como simbólicas (SÁ; SIQUARA; CHICON, 2015).

Reis, Pereira e Almeida (2016) postulam que a pessoa com TEA é marcada pelo atraso em dois domínios: interação social e comunicação/linguagem, embora tenha-se assumido recentemente que estas duas dimensões sejam indissociáveis (AMERICAN PSYCHIATRIC ASSOCIATION, 2018). Uma série de trabalhos conduzidos, sobretudo a partir dos anos 2000, têm se debruçado sobre os processos de interação social de crianças com TEA. Parte deles tem enfocado nas representações destas crianças (p.e. BAGAROLLO; RIBEIRO; PANHOCA, 2013), outra parte, no próprio impacto das práticas pedagógicas diante de suas particularidades comportamentais (SOUZA, 2003; GOMES; NUNES, 2014)

Ao se considerar os possíveis impactos dos contextos na interação social destes indivíduos, alguns trabalhos têm sido realizados procurando identificar os possíveis desdobramentos de programas de intervenção sobre as habilidades sociocomunicativas destas crianças. Ferreira e Munster (2017), por exemplo, avaliaram as habilidades sociocomunicativas, antes e após uma proposta de intervenção em Educação Física, por meio do instrumento denominado Sistema de Avaliação das Habilidades Sociais (SSRSBR). O programa foi constituído por sessões de dança, circo, ginástica geral, esportes e 
http://dx.doi.org/10.5902/1984686X36641

lutas. O protocolo de avaliação compreendeu as dimensões responsabilidade, asserção positiva, autocontrole, autodefesa e cooperação e foi desenvolvido por meio de 24 sessões de 40 minutos. A partir da intervenção foi identificada melhora nos escores Global das habilidades sociocomunicativas, principalmente nas categorias responsabilidade, asserção positiva e autocontrole (FERREIRA; MUNSTER, 2017).

Em outras palavras, essas habilidades sociocomunicativas parecem ser consideravelmente influenciadas por programas de intervenção em Educação Física, sobretudo por aqueles cujas propostas estejam voltadas a criar espaços de aproximação e troca entre crianças e jovens, como grande parte das atividades desenvolvidas em programas de atividade motora (FERREIRA; MUNSTER, 2017; HOUSTON-WILSON, LIEBERMAN, 2013; SANTOS et al, 2017).

Na concepção da educação inclusiva, conforme proposta por Stainback \& Stainback (1999), as interações contribuem para que a criança esteja envolvida com os grupos sociais, estabelecendo relações sociais para que se tenha a percepção de pertencimento e identificação ao grupo. Para Gimenez (2015), um dos mecanismos chave ao processo de inclusão corresponde ao desenvolvimento do motivo de afiliação, desenvolvido em torno da criança com deficiência. Em especial, este motivo seria evidenciado pelo acolhimento da criança com deficiência em um grupo de amigos. Segundo o autor, o contexto escolar pode representar um fator facilitador (ou não) para a aproximação entre elas.

Ao se considerar o vínculo como uma interação dialética entre indivíduo e ambiente, tal relação está baseada em conceitos estabelecidos pelos grupos sociais. No caso deste estudo, estes grupos corresponderiam aos identificados na escola e, mais especificamente, na sala de aula. Na prática, muitas vezes percebe-se que, mesmo aqueles alunos com deficiência que se encontram inseridos no sistema regular de ensino, continuam sendo isolados dos seus companheiros de turma sem deficiência (BATISTA; ENUMO, 2004; BAYDIK; BAKKALOĞLU, 2009; ANHÃO; PFEIFER; SANTOS, 2010).

Alguns estudos com este prisma tentaram descrever as relações entre os sujeitos com e sem deficiência. Anhão, Pfeifer e Santos (2010) e Silva (2000), por exemplo, por meio de uma pesquisa que investigou as interações sociais no nível da Educação Infantil, destacaram a importância da inserção e interação das crianças com deficiência em ambiente escolar, uma vez que julgam que promovem novas formas de pensar, agir e atuar em relação ao meio em que estão inseridas. 
http://dx.doi.org/10.5902/1984686X36641

Em outra pesquisa, Batista e Enumo (2004) apresentaram o status sociométrico de três alunos da primeira série do Ensino Fundamental. O status sociométrico é definido pelo número de indicações feitas a um indivíduo geradas por perguntas: uma de caráter positivo (aceitação) e outra de caráter negativo (rejeição). Para tanto, é utilizada uma situação real para estimular as escolhas dos sujeitos da forma mais fidedigna possível. O teste sociométrico é aplicado com todas as pessoas do círculo social, podendo limitar ou não a quantidade de indicações, sejam elas positivas ou negativas. Dessa forma, é possível identificar as conexões de cada sujeito em relação ao grupo e sua posição (status). Assim, aquele que possui maior indicação positiva é considerado "popular", o que possui poucas ou nenhuma indicação positiva é considerado "isolado". Já aquele que possui muitas indicações negativas é considerado "excluído", e por fim, aquele que possui poucas ou nenhuma indicação negativa é considerado "não-excluído" (ALVES, 1972).

Batista e Enumo (2004) concluíram que dois dos alunos apresentaram status de excluídos ou isolados ao grupo, ao passo que, apenas um deles apresentou o status de popular. Porém, durante as sessões de observação todos passavam, a maior parte do tempo do intervalo, sozinhos e a iniciativa para interação era, na maioria das vezes, iniciada por outros sujeitos e não pelos alunos-alvo. O encerramento da conversa, contudo, se dava pelos alunos-alvo. Tal fato implica na necessidade de se investigar a natureza e o grau das interações estabelecidas entre as crianças.

Baydik e Bakkaloglu (2009) desenvolveram um estudo comparativo do status sociométrico entre estudantes com e sem deficiência do Ensino Fundamental, em uma escola de baixa renda. $O$ estudo se debruçou sobre os efeitos de diferentes variáveis no processo de interação social de alunos com deficiência, dentre elas: gênero, idade, aparência física, competência acadêmica, habilidades sociocomunicativas e problemas de comportamento. Os resultados obtidos mostraram que os alunos com deficiência são menos aceitos pelo grupo em razão de sua competência acadêmica, sua aparência física e seus problemas de comportamento. Ao se comparar este status com o de alunos sem deficiência, identifica-se que a exclusão ocorreria por motivos similares.

Pijl, Frostad e Flem (2008), por exemplo, identificaram que crianças autistas e com deficiência intelectual são frequentemente menos populares entre os colegas de turma, além de participarem menos ativamente de atividades orientadas ao grupo. Ao mesmo tempo, esses autores também identificaram que estas crianças se beneficiam de forma 
http://dx.doi.org/10.5902/1984686X36641

importante da presença de outras crianças, utilizadas como tutoras nos contextos de aprendizagem.

Em se tratando dos processos de interação social, parece existir um consenso na literatura de que as aproximações entre as crianças poderiam ser favorecidas por algumas condições. Dentre elas, pode-se destacar as concepções e a fundamentação dos professores (conf. RHEAMS; BAIN, 2005; WAINMANN et al. 2012; CAMARGO et al. 2016); as concepções das demais crianças (conf. CLEEG et al. 2008; TACHIBANA et al., 2017) e do próprio contexto, o qual envolveria desde o ambiente físico (conf. KIRKEBY; GRANGAARD, 2016) até as propostas pedagógicas (conf. MEYER, 2001; CESAR; SANTOS, 2006; MACKAY et al. 2007; SANDERSON, 2008; RIX et al. 2009, WENDELBORG; KVELLO, 2010; QI; HA, 2012; BEIERS; DERBY; MCLAUGHLIN, 2016; GIMENEZ; ONHA, 2016).

Um dos achados de alguns trabalhos é o de que a interação social estabelecida entre as crianças e jovens poderia ser favorecida por meio de tarefas com demanda colaborativa (GRENWAY, 2000; RIX et al., 2009). Estas tarefas estariam associadas ao desenvolvimento de projetos coletivos, em geral temáticos, ou mesmo a desafios propostos pelos professores a serem cumpridos por um determinado grupo. Vale ressaltar, ainda, que as configurações desse contexto apresentariam desdobramentos mais efetivos sobre os processos de interação social do que, supostamente, a própria natureza das deficiências ou dificuldades de aprendizagem (WENDELBORG; KVELLO, 2010). Outra questão chave corresponde à natureza das interações estabelecidas entre as crianças com e sem deficiência. Pawson et al. (2010) argumentam sobre a necessidade de se investigar o tipo e a magnitude da interação estabelecida entre as crianças com maior aprofundamento, tendo em vista contribuir de forma mais efetiva para a organização das propostas e dos espaços de intervenção.

Ao se levar em consideração as efetivas contribuições do contexto sobre o processo de inclusão, entende-se que as possibilidades de interação social entre as crianças podem sofrer influência do nível da Educação Básica em que se encontram.

Fundamentalmente, os diferentes níveis da Educação Básica interferem direta e indiretamente na aceitação e na exclusão dos alunos. Por exemplo, a cobrança e a valorização das competências acadêmicas, item fundamental para estabelecimento das relações e vínculos afetivos, é mais presente no Ensino Fundamental do que na Educação Infantil, (BAYDIK; BAKKALOĞLU, 2009). Makida-Dyonisio, Martins e Gimenez (2016) 
http://dx.doi.org/10.5902/1984686X36641

levantam uma série de elementos que contribuiriam substancialmente para uma ambiência diferente para a inclusão na Educação Infantil quando comparada ao Ensino Fundamental. Dentre os fatores destacados por esses autores, encontram-se a relação entre pais ou responsáveis e professores, a relação entre professores e alunos, as concepções e orientações do projeto pedagógico. Vale ressaltar que as diferenças de concepção e a própria orientação do projeto pedagógico contribuiriam de forma preponderante para definir a utilização de espaços e propostas de atividade, elementos reconhecidamente determinantes para a possibilidade de aproximação entre as crianças.

Diante da importância das interações sociais estabelecidas entre as crianças, a realização de um estudo exploratório acerca das possibilidades de interação, comparando diferentes níveis da Educação Básica, é salutar, a fim de se desenvolverem subsídios à compreensão do processo de inclusão.

Assim, o objetivo do presente trabalho foi comparar o status sociométrico de alunos com deficiência intelectual e com transtorno do espectro do autismo nos âmbitos da Educação Infantil e do Ensino Fundamental.

\section{Traçado Metodológico}

A pesquisa foi realizada em uma escola pública estadual situada no município de Santo André, Estado de São Paulo. A escola foi escolhida por possuir, em seu quadro de alunos, crianças com várias deficiências e em diferentes graus, matriculadas no ensino regular e também por apresentar os níveis de Educação Infantil e Ensino Fundamental utilizando o mesmo espaço físico. A referida unidade escolar abriga turmas de crianças de 04 e 05 anos ( $2^{\circ}$ ciclo inicial e $2^{\circ}$ ciclo final) no nível de Educação Infantil e crianças de 06 a 10 anos (1ํ ao $5^{\circ}$ ano) no Ensino Fundamental, nos períodos matutino e vespertino. A turma da El estudada era composta por 25 crianças, sendo 10 meninos e 15 meninas. Já a turma do EF possuía 26 crianças, das quais 15 eram meninos e 11 meninas.

Para a análise do status sociométrico das crianças com deficiência, foi necessária a participação de todos os alunos das duas classes como sujeitos da pesquisa. $O$ estudo foi submetido e aprovado pelo Comitê de Ética da Universidade Cidade de São Paulo UNICID com o protocolo número. 1.368.482.

Após a autorização da diretora da Unidade escolar, a primeira ação realizada foi uma reunião com os pais dos alunos para explicar os objetivos do projeto de pesquisa e solicitar a autorização dos mesmos para que seus filhos pudessem participar do trabalho. Não 
http://dx.doi.org/10.5902/1984686X36641

havendo objeções, foi dado início à pesquisa. A coleta de dados foi realizada no corredor das salas, local com pouca movimentação, no período da tarde, em duas etapas: Etapa 1 - fotografar as crianças para confecção do carômetro'; Etapa 2 - aplicação do teste sociométrico individualmente. Assim, mediante a autorização de seus pais foram tiradas fotos das crianças alvo e apresentadas aos seus colegas. A utilização deste instrumento é recomendada, tendo em vista evitar a exposição destas crianças da pesquisa (MOLINA; DEL PRETE, 2007).

O procedimento metodológico foi adaptado para a idade com base no Teste Sociométrico descrito por Alves (1972). Foi aplicado, por meio da apresentação de fotografias de todos os 51 participantes para os quais foram feitas verbalmente as seguintes perguntas: Questão 1 (Q1) - dentre seus colegas, quais você mais gostaria de brincar? e a Questão 2 (Q2) - dentre seus colegas, quais você menos gostaria de brincar?

Cumpre destacar que se solicitou às crianças que apresentassem verbalmente três indicações de colegas para cada questão. Em especial, desenhos de pesquisa semelhantes foram adotados em estudos anteriores (BATISTA; EMUNO, 2004, LOPES; MAGALHÃES, 2003, MOLINA; DEL PRETTE, 2007).

Como critério de inclusão no estudo, a classe deveria ter pelo menos um aluno com deficiência em seu quadro e todos deveriam ter, no mínimo, dois meses de convívio escolar. Dados na literatura ressaltam que crianças com e sem deficiência comumente adotam como amigo aquele que está em proximidade física, despertando o sentimento de pertencimento ao grupo. A adoção desse critério justifica-se para comparar os dados da construção da rede de relações sociais desta pesquisa com os dados de pesquisas já existentes (p.e. PIJL; FROSTAD; FLEM, 2008; BAYDIK; BAKKALOGLU, 2009).

Foram selecionados como estudantes-alvo para a avaliação dos demais alunos desta pesquisa, crianças com deficiência intelectual e com TEA, independentemente do tipo e grau de deficiência ou da limitação que apresentavam. Dentre os respondentes, foram excluídos do estudo os sujeitos com frequência de convívio inferior a dois meses, bem como aqueles que se negaram a responder o teste.

Com a aplicação do teste é possível identificar o status sociométrico de todos os participantes. Cada turma escolhida apresentava dois alunos com deficiência, os quais foram considerados alunos-alvo da nossa pesquisa. Como indicado por Alves (1972), com intuito de preservar a identidade das crianças, todas elas foram identificadas por siglas. Assim analisamos os seguintes perfis: 
http://dx.doi.org/10.5902/1984686X36641

Quadro 1 - Caracterização dos sujeitos participantes da pesquisa

\begin{tabular}{|c|c|c|c|c|}
\hline $\begin{array}{l}\text { SIGLA - } \\
\text { Nome do } \\
\text { indivíduo }\end{array}$ & $\begin{array}{c}\text { Nível da Educação } \\
\text { Básica }\end{array}$ & Gênero & Idade & Tipo de deficiência \\
\hline$A D$ & Educação Infantil & Masculino & $\begin{array}{c}5 \text { anos e } 2 \\
\text { meses }\end{array}$ & Intelectual \\
\hline DM & Educação Infantil & Masculino & $\begin{array}{c}5 \text { anos e } 6 \\
\text { meses }\end{array}$ & $\begin{array}{c}\text { Transtorno do } \\
\text { espectro de autismo }\end{array}$ \\
\hline $\mathrm{KA}$ & Ensino Fundamental & Masculino & $\begin{array}{c}6 \text { anos e } 3 \\
\text { meses }\end{array}$ & Intelectual \\
\hline DA & Ensino Fundamental & Masculino & $\begin{array}{c}6 \text { anos e } 10 \\
\text { meses }\end{array}$ & $\begin{array}{c}\text { Transtorno do } \\
\text { espectro de autismo }\end{array}$ \\
\hline
\end{tabular}

Fonte: elaborado pelos autores a partir de Makida-Dyonisio (2017).

Dentre os participantes, conforme ilustra o quadro, o aluno $A D$ e o aluno DM pertencem à Educação Infantil e KA e DA, ao Ensino Fundamental. AD apresenta Deficiência intelectual e, além dela, apresenta hemiplegia espástica como sequela de paralisia cerebral. Esta criança estava há um ano na referida escola e é considerada pelos professores uma criança relativamente autônoma e comunicativa. DM ingressou na mesma unidade escolar um ano antes, ocasião em que fora concluído o diagnóstico de TEA. De acordo com os profissionais da escola, esta criança tinha muita dificuldade de lidar com frustrações e em se comunicar com o seu grupo. Por outro lado, ela apresentava relativa autonomia para atividades da vida diária, como é o caso da alimentação.

No que diz respeito às crianças do Ensino Fundamental, KA apresentava o diagnóstico de DI e estava matriculada na unidade escolar há dois anos. Tratava-se de uma criança com muita dificuldade de atenção, embora com razoável condição de comunicação, embora apresentasse um bom relacionamento com o grupo. Finalmente DA, também apresentava diagnóstico de TEA e ingressou na unidade escolar no mesmo período que $\mathrm{KA}$. Tratava-se de uma criança que se comunicava relativamente bem e apresentava bom relacionamento com o grupo.

\section{Procedimentos}

Para cada turma, foi construído um sociograma de identificação das escolhas. Nesta análise, verificou-se: a consistência das respostas das crianças, a possível existência de determinada(s) criança(s) com mais indicações nas escolhas positivas e negativas e a possível existência de crianças não mencionadas (ou pouco mencionadas) no teste.

Para a classificação sociométrica dos indivíduos, foram adotados pressupostos de probabilidade como critério estatístico, os quais levaram em consideração os índices 
probabilísticos das escolhas. Estas foram relacionadas com as notas conseguidas no teste. Além disso, serviram como base para o cálculo dos limiares de probabilidade, descritos por Moreno e Jennings (apud ALVES, 1972). Vale ressaltar que os critérios de confiabilidade adotados corresponderam a um $p<0.05$.

O objetivo do cálculo dos limiares probabilísticos foi a identificação de certos limites que possibilitassem a classificação sociométrica dos indivíduos de um grupo, em função do número de escolhas, rejeições, etc. obtidas. No teste sociométrico, as indicações foram pautadas na convivência entre os indivíduos. Desse modo, a análise dos dados foi realizada em dois grupos: a) Educação Infantil (El), b) Ensino Fundamental (EF).

Os limiares delimitam quem está na curva da média ou nas extremidades, tanto com baixa indicação, como com alta indicação. Em outras palavras, esta dimensão é calculada pela diferença entre escolhas e rejeições recebidas por cada sujeito (ALVES, 1972). A classificação de cada sujeito dentro dos cinco tipos de status social foi realizada de acordo com as categorias popular, isolado, excluído, não-excluído e mediano.

Os quadros abaixo indicam o número de indicações necessárias para a classificação do status em destaque da média. Eles compreendem a questão, o número de indicações recebidas pela criança e o seu respectivo status sociométrico.

Quadro 2 - Limiares probabilísticos do status sociométrico na Escola de Educação Infantil

\begin{tabular}{|c|c|c|c|c|c|}
\hline \multicolumn{7}{|c|}{ Notas significativas do grupo da El } \\
\hline Questão & $\begin{array}{c}\text { Número de } \\
\text { indicações } \\
\mathrm{p}<0.05\end{array}$ & $\begin{array}{c}\text { Status } \\
\text { sociométrico }\end{array}$ & Questão & $\begin{array}{c}\text { Número de } \\
\text { indicações } \\
\mathrm{p}<0.05\end{array}$ & $\begin{array}{c}\text { Status } \\
\text { sociométrico }\end{array}$ \\
\hline 1 & 1 ou menos & Isolado & 1 & 4 ou mais & Popular \\
\hline 2 & 1 ou menos & Não-excluído & 2 & 5 ou mais & Excluído \\
\hline
\end{tabular}

Fonte: elaborado pelos autores a partir de Makida-Dyonisio (2017).

Quadro 2 - Limiares probabilísticos do status sociométrico na Escola de Educação Infantil

\begin{tabular}{|c|c|c|c|c|c|}
\hline \multicolumn{7}{|c|}{ Notas significativas do grupo da EF } \\
\hline Questão & $\begin{array}{c}\text { Número de } \\
\text { indicações } \\
\mathrm{p}<0.05\end{array}$ & $\begin{array}{c}\text { Status } \\
\text { sociométrico }\end{array}$ & Questão & $\begin{array}{c}\text { Número de } \\
\text { indicações } \\
\mathrm{p}<0.05\end{array}$ & $\begin{array}{c}\text { Status } \\
\text { sociométrico }\end{array}$ \\
\hline 1 & 1 ou menos & Isolado & 1 & 4 ou mais & Popular \\
\hline 2 & 1 ou menos & Não-excluído & 2 & 4 ou mais & Excluído \\
\hline
\end{tabular}

Fonte: elaborado pelos autores a partir de Makida-Dyonisio (2017). 
http://dx.doi.org/10.5902/1984686X36641

1. A categoria "popular" foi formada por todos os sujeitos com índice de preferência social maior que quatro indicações recebidas na Questão 1, em ambos os grupos.

2. A categoria "isolado" foi constituída por sujeitos com preferência social menor que um na Questão 1, ou seja, por aqueles que receberam 1 indicação ou zero, em ambos os grupos.

3. A categoria "excluído" foi constituída a partir do resultado obtido na Questão 2, incluindo-se sujeitos com mais de cinco indicações da Educação Infantil e menos que 4 do Ensino Fundamental.

4. A categoria "Não-excluídos" foi constituída por sujeitos que receberam uma ou zero indicações na Questão 2, para ambos os grupos.

5. A categoria "Medianos" foi composta por sujeitos que não se encaixaram nos perfis anteriores.

\section{Resultados e Discussões}

Os resultados a seguir estão apresentados em forma de sociograma, que representa as indicações emitidas e recebidas individualmente pelas crianças analisadas. A partir do sociograma, é possível analisar a quantidade das interações, além de identificar detalhadamente a rede de interação dos sujeitos.

Assim, o aluno-alvo AD e suas interações estão representados na Figura 1. O mesmo emitiu quatro indicações positivas na Q1 e quatro indicações negativas na Q2, sendo a indicação dupla para o mesmo indivíduo DM. Não houve indicações recíprocas, porém, recebeu uma indicação positiva de LI e três indicações negativas de AS, RA e LA.

Figura 1 - Sociograma AD - Educação Infantil

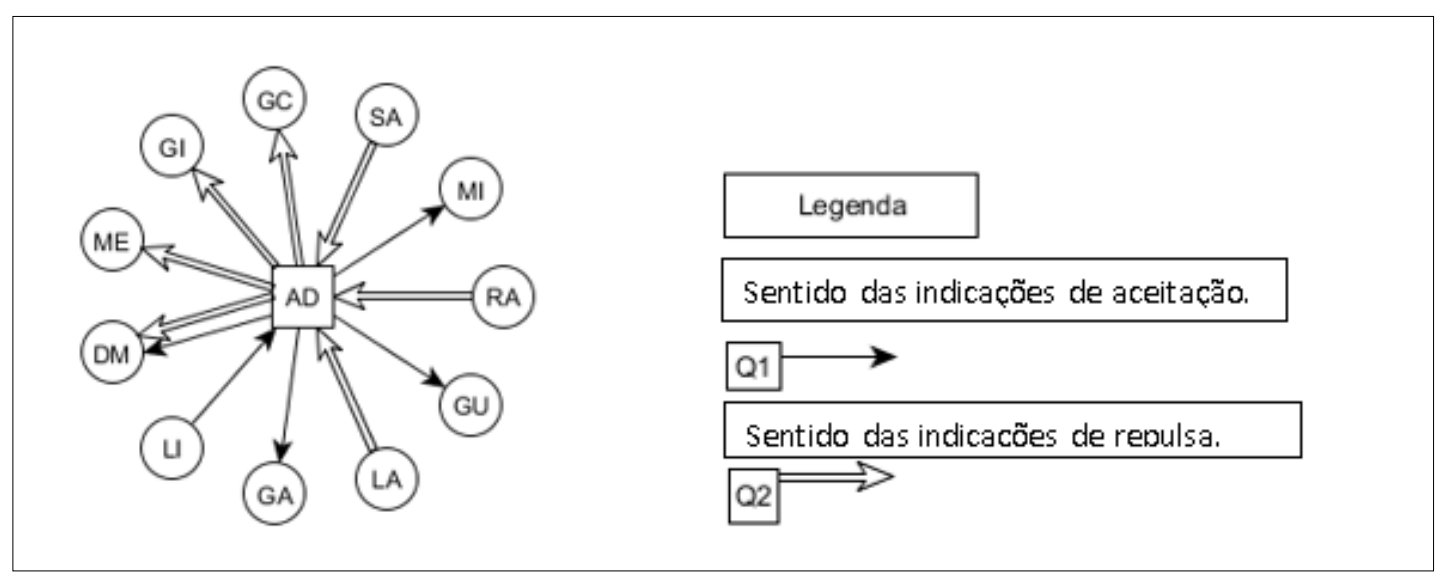

Fonte: elaborado pelos autores a partir de Makida-Dyonisio (2017). 
O segundo aluno-alvo, DM (FIGURA 2), realizou três indicações na Q1 (ME, Gl e GA) e 3 indicações na Q2 (DG, GU e SA), recebeu duas indicações na Q1 (AD e KE) e quatro indicações na Q2 (AD, TY, JU e SC). Não houve indicações recíprocas. Porém, houve duas indicações por AD, uma positiva e outra negativa (Q1 e Q2).

Figura 2 - Sociograma DM - Educação Infantil

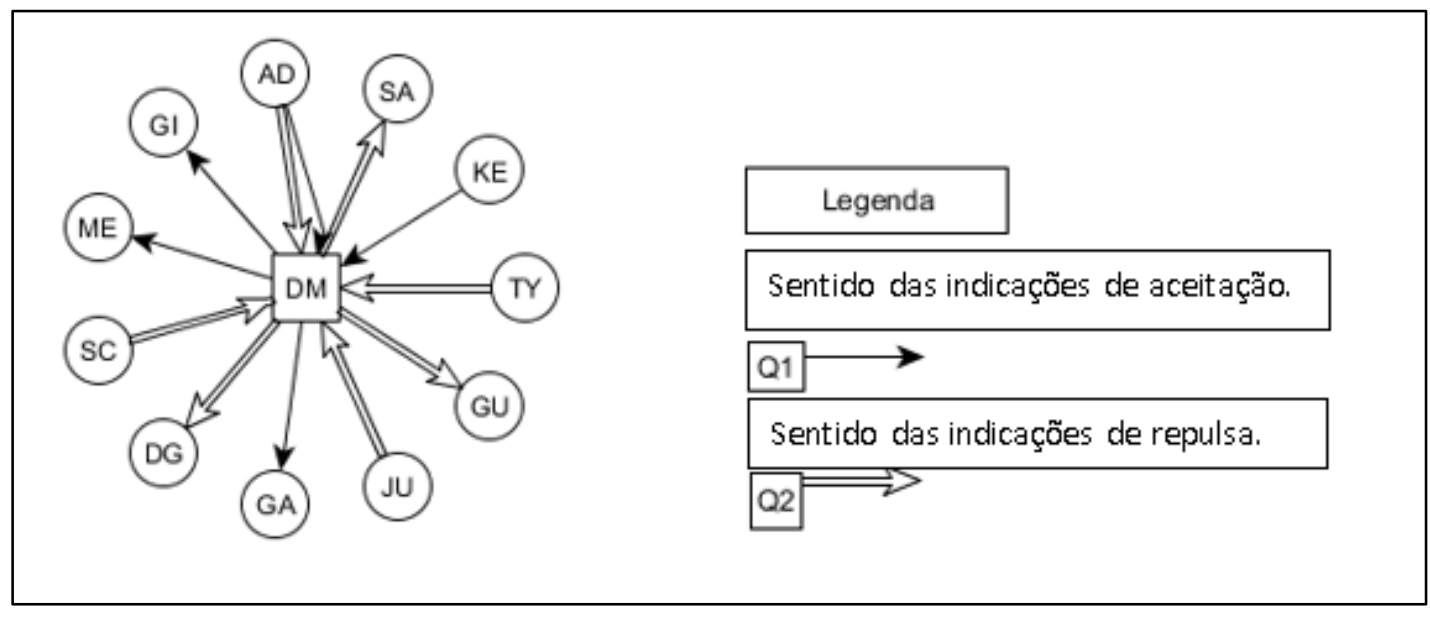

Fonte: elaborado pelos autores a partir de Makida-Dyonisio (2017).

Na Figura 3, estão representadas as indicações de DA, das quais foram emitidas três indicações na Q1 (DV, AL e RY) e na Q2 (GI, DI e AB). Esse aluno recebeu também, três indicações positivas na Q1 (DI, KA e LE) e uma indicação na Q2 (FI). Porém, com DI, KA recebeu uma indicação positiva na Q1 e emitiu uma indicação negativanaQ2, caracterizando oposição de sentimentos.

Figura 3 - Sociograma DA - Ensino Fundamental

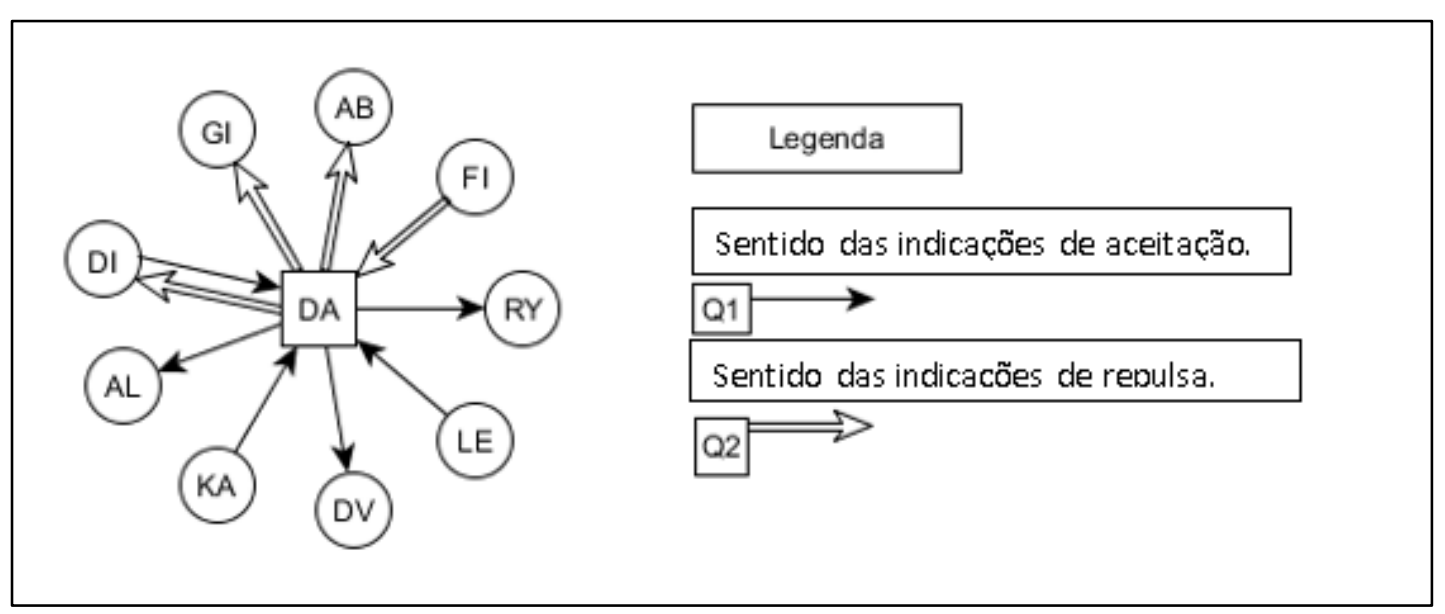

Fonte: elaborado pelos autores a partir de Makida-Dyonisio (2017). 
O aluno-alvo KA (FIGURA 4) realizou três indicações na Q1 ena Q2, sendo Q1 - DA, JU e KA; Q2 - GU, FE e DM. Ele recebeu cinco indicações na Q1 (UM, DV, JU, LI e AL), e três na Q2 (RY, IS e DI), das quais uma indicação foi recíproca com DI na Q1.

Figura 4 - Sociograma KA - Ensino Fundamental

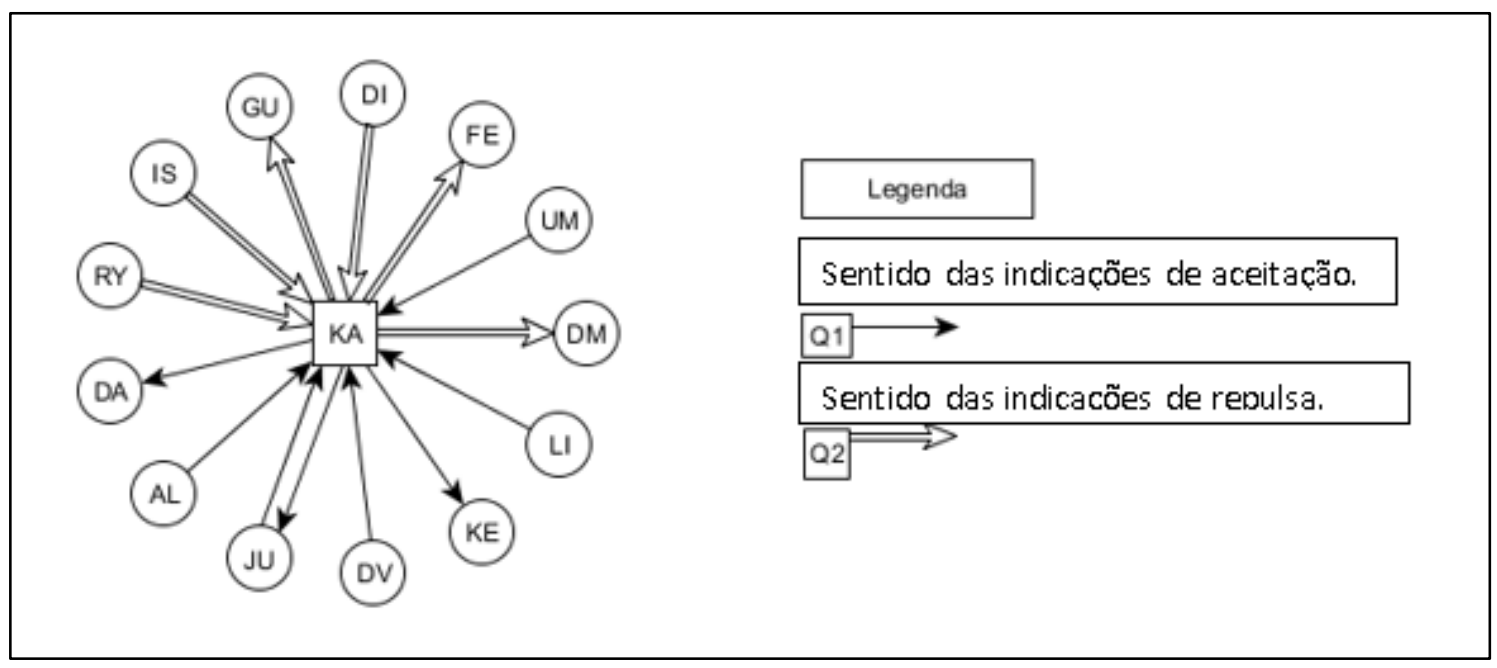

Fonte: elaborado pelos autores a partir de Makida-Dyonisio (2017).

Na Tabela1, é possível analisar os status sociométricos dos alunos-alvo da El e EF que apresentaram notas dentro dos limites inferiores e superiores.

Tabela 1 - Análise e classificação das escolhas recebidas pelos sujeitos

\begin{tabular}{|c|c|c|c|}
\hline $\begin{array}{l}\text { SIGLA - Nome do } \\
\text { indivíduo }\end{array}$ & $\begin{array}{l}\text { Status } \\
\text { Sociométrico }\end{array}$ & Tipos de deficiência & Nível de Ensino \\
\hline$A D$ & Isolado & Intelectual & Educação Infantil \\
\hline DM & Excluído & $\begin{array}{c}\text { Transtorno do espectro de } \\
\text { autismo }\end{array}$ & Educação Infantil \\
\hline $\mathrm{KA}$ & Popular & Intelectual & Ensino Fundamental \\
\hline DA & Não-excluído & $\begin{array}{l}\text { Transtorno do espectro de } \\
\text { autismo }\end{array}$ & Ensino Fundamental \\
\hline
\end{tabular}

Fonte: elaborado pelos autores a partir de Makida-Dyonisio (2017).

Ao se comparar os níveis da Educação Básica, identifica-se que os alunos da Educação Infantil (AD, DM) obtiveram status mais negativos que os do Ensino Fundamental (KA, DA). Tal fato pode ser explicado pelo tempo de convivência entre os indivíduos. Odom et al. (2000) apresentam alguns facilitadores para a inclusão. Para o autor, um dos quesitos 
está relacionado à interação de crianças com e sem deficiência em ambientes escolares e comunitários. Assim, há a possibilidade de que, a partir da convivência entre os alunos em sala de aula, ocorra um desdobramento nas configurações de vínculos afetivos e uma maior aceitação dos indivíduos, o que os classifica como medianos ao grupo.

Apesar das diferenças entre os contextos, é preciso considerar sua individualidade. $\mathrm{Na}$ Educação Infantil, AD não obteve dados de exclusão em relação ao grupo, porém, possui pouca ou mínima interação, o que o define como "isolado". Tal constatação denota um esquecimento do grupo em relação a ele perante as indicações no teste. Em contrapartida, DM aparece como "excluído" e tal exclusão pode ser desencadeada por inúmeros fatores, porém, é possível destacar dois que são fundamentais nesse processo de inclusão, dentre eles comportamento e a competência acadêmica (BAYDIK; BAKKALOGLU, 2009). Em especial, na Educação Infantil, o fator comportamento seria determinante para a possível rejeição.

Ao se levar em consideração o perfil do aluno DM, entende-se que a sua condição de isolamento possa ter influenciado os tipos de interação com os demais colegas de sala. É possível também que o comportamento da criança diagnosticada com TEA, também identificado por dificuldades para lidar com frustrações, manifestando agressividade diante de condições adversas, tenha contribuído para a dificuldade em relacionar-se com os colegas, o que justificaria o status de "excluído". Cumpre destacar que estas são características apontadas nos prontuários desta criança na escola, utilizados como base para o presente estudo.

É crucial ressaltar também que esta explicação se torna ainda mais plausível ao se considerar que o outro motivo de exclusão corresponderia à competência acadêmica, a qual não é muito valorizada neste âmbito da Educação Básica (ALMEIDA, 2012; MAKIDADYONISIO; MARTINS; GIMENEZ, 2016). Talvez seja possível inferir que, em se tratando da Educação Infantil, as possibilidades de interação social da criança, sejam preponderantes para as suas possibilidades de inclusão em relação à competência acadêmica.

Levando em consideração os alunos do Ensino Fundamental, a Tabela 1 indica que KA aparece como "popular" e DA é considerado "não-excluído". Com esses resultados, é possível perceber a efetividade das relações durante o processo de escolarização. Camargo e Bosa (2009, p. 72) afirmam que "a qualidade dessas primeiras experiências provavelmente influirá na adaptação social nos anos escolares subsequentes" 
http://dx.doi.org/10.5902/1984686X36641

Assim, o status de "popular" de KA e o status "não-excluído" de DA podem ser resultado de um processo de relacionamentos instituídos ao longo dos anos, tendo em vista que os alunos permanecem na mesma unidade escolar desde a Educação Infantil, somando cerca de, no mínimo, três anos de convivência, sem levar em consideração as possíveis relações estabelecidas em outros ambientes comunitários.

O terceiro questionamento é referente aos tipos de deficiência e à associação com o status sociométrico. DM e DA possuem estereotipias características do transtorno do espectro de autismo, das quais a mais relevante é a dificuldade de interação social e comunicação/linguagem (REIS; PEREIRA; ALMEIDA, 2016; GONÇALVES et al., 2004). É possível inferir que houve impacto de forma negativa no seu status sociométrico. Contudo, alguns estudos apontam os benefícios no desenvolvimento desses alunos ingressos no ambiente escolar, desde a mais tenra idade (CAMARGO; BOSA, 2009). Um dos pontos positivos apontados por Barbosa (2007) é a interiorização de normas, valores, funções cognitivas, conhecimentos e práticas pela convivência com novos sujeitos de interação. Além disso, são apontados avanços no seu desenvolvimento global por parte da literatura (REIS; PEREIRA; ALMEIDA, 2016; GONÇALVES et al., 2004).

Por outro lado, os alunos com deficiência intelectual apresentaram status mais positivos em relação aos alunos com TEA, inclusive em relação ao $\mathrm{KA}$, denominado como popular. Alguns estudos apontam a dificuldade de interação social, porém, a intervenção pedagógica é um ponto facilitador no desenvolvimento e nas habilidades sociais (FERREIRA; MUNSTER, 2017).

Em linhas gerais, embora exista uma mudança de projeto da Educação Infantil para o Ensino Fundamental, bem como se entenda que o processo de interação entre as crianças possa ser afetado pela natureza de sua deficiência, percebe-se que ambas não foram suficientes para impactar substancialmente o grau de interação social estabelecido entre as crianças (ALMEIDA, 2012). Em outras palavras, embora houvesse a hipótese de uma possibilidade de exclusão maior no Ensino Fundamental, em decorrência da própria orientação deste nível da Educação Básica, isto não foi identificado.

No Ensino Fundamental, a criança é exigida pelo grau de competência e, se ela não consegue atingir o padrão de excelência determinado pelo grupo, ela pode ser excluída (ALMEIDA, 2012). Contudo, como elas estão no primeiro ano do Ensino Fundamental, contexto caracterizado por nível de exigência acadêmica diminuído, não possuem tanta dificuldade e diferença na compreensão dos conteúdos, contribuindo para explicar a não 
http://dx.doi.org/10.5902/1984686X36641

rejeição. Seria possível pressupor que, na medida em que avançam os anos do Ensino Fundamental, o nível de exigência aumenta e a dificuldade fica mais acentuada, aumentando a possibilidade de exclusão e rejeição nos anos posteriores.

É possível considerar ainda que, pelo fato de se tratar de uma mesma escola, não tenha existido um impacto preponderante da cultura escolar sobre os resultados. Possivelmente, se a análise se debruçasse sobre escolas com características diferentes, seriam encontrados elementos mais fortes associados às concepções que, ao permearem as estruturas e as práticas pedagógicas, poderiam proporcionar desdobramentos sobre os meios de interação social existentes (CAMARGO et al., 2016).

Um dos pressupostos é o de que os processos de comunicação aluno-aluno e professor-aluno seriam obstáculos importantes em relação ao processo de inclusão, cumprindo destacar que, à medida que se avança nos anos da Educação Básica, eles podem se tornar mais difíceis em decorrência da natureza das propostas pedagógicas dos diferentes níveis de ensino, do aumento do número de professores e da diminuição do contato entre professores e alunos e também, entre pais e professores (MAKIDADYONISIO; MARTINS; GIMENEZ, 2016).

O conjunto de dados também possibilita inferir que, possivelmente, as barreiras de comunicação, elas impostas pela deficiência ou não, são cruciais para o processo de inclusão (MAKIDA-DYONISIO; MARTINS; GIMENEZ, 2016). É possível que esta barreira de proficiência aumente ao longo dos anos do Ensino Fundamental até o Ensino Médio. Em parte, isto explicaria a razão pela qual há mais crianças com deficiência e TEA matriculadas no Ensino Fundamental do que no Ensino Médio, o que corrobora com estudos anteriores (BATISTA; ENUMO, 2004; BAYDIK; BAKKALOĞLU, 2009; ANHÃO; PFEIFER; SANTOS, 2010). A orientação dos projetos dos ciclos, a gestão dos espaços e tempos, as configurações das salas, as articulações entre os professores podem ser determinantes ao processo de inclusão (MAKIDA-DYONISIO; MARTINS; GIMENEZ, 2016). $O$ arranjo entre esses elementos sofreria grande mudança com o avanço da escolarização, em especial isto seria percebido pelo aumento do número de professores, empobrecimento das relações entre eles, pela diminuição da frequência de uso de espaços de convivência e práticas corporais, o que pode contribuir de forma significativa para a diminuição das possibilidades de interação social entre as crianças e jovens.

Vale ressaltar, ainda, a necessidade de uma análise mais detalhada sobre os processos de intervenção em longo prazo. A utilização do sociograma possibilita um retrato 
http://dx.doi.org/10.5902/1984686X36641

momentâneo que pode ser modificado ao se considerar um período de tempo maior. Desse modo, sugere-se que este recurso diagnóstico também possa ser útil como forma de subsídio para o acompanhamento os impactos de programas de intervenção. Entende-se ainda que seja importante o desenvolvimento de estudos que procurem investigar as possíveis mudanças no status sociométrico de crianças diante de períodos de tempo maiores, como ao longo de um ano letivo ou mesmo de um ciclo da Educação Básica. Cuckle \& Wilson (2002) advertem que, em se tratando de populações-alvos de inclusão, os resultados sobre o processo de interação podem depender de um tempo maior, haja vista as particularidades inerentes a essas populações. Daí a necessidade de que se desenvolvam outros estudos que acompanhem longitudinalmente os grupos ou mesmo que envolvam outras faixas etárias (JOHNSON et al., 2012).

Outro aspecto crucial diz respeito à ausência de diferenças substanciais no processo de interação entre indivíduos com deficiência intelectual e TEA. Embora parte da literatura possa sugerir uma dificuldade um pouco mais acentuada por parte das crianças com TEA nos processos de interação quando comparados aos indivíduos com DI (MACKAY et al., 2007), os achados do presente estudo não vão nesta direção. Desse modo, entende-se, também, a necessidade de que futuros estudos busquem identificar as possíveis associações entre as características sociocomunicativas das crianças participantes e o seu status sociométrico. Embora esta questão não tenha feito parte do escopo do presente estudo, assume-se que ela mereça maior atenção por parte de futuros trabalhos.

É possível que características marcantes do contexto escolar tenham prevalecido para criar momentos e espaços de aproximação entre as crianças, o que segundo Wendelborg \& Kvello (2009) corresponderia a uma condição mais determinante ao processo de interação do que a própria natureza ou grau de deficiência ou dificuldade. Comporiam estes contextos, desde os layouts das escolas até os espaços de convivência como playgrounds, brinquedotecas e bosques, que, certamente, criam condições efetivas de aproximação entre as crianças. Além disso, estes espaços apresentariam forte relação com a natureza das atividades desenvolvidas em suas dependências (SANTOS; MARTINS; GIMENEZ, 2019).

Esse argumento remete à necessidade de se analisar os contextos de interação social de forma mais aprofundada, levando em consideração parâmetros como a estrutura física (KIRKEBY; GRANGAARD, 2016) e as propostas pedagógicas desenvolvidas (BEIERS et al., 2016). 
Os resultados dessa pesquisa permitem inferir que as possibilidades de aceitação e, consequentemente, de inclusão de alunos com deficiência podem ultrapassar o primeiro nível de integração física descrita por Edler de Carvalho (1991). Com tais resultados, é presumível que haja também a "integração social" (EDLER DE CARVALHO, 1991) e o estabelecimento de vínculos sólidos entre os alunos com e sem deficiência. Em outras palavras, a deficiência intelectual e o Transtorno do Espectro do Autismo não representaram impedimentos consideráveis ao processo de interação social.

Contudo, é nítido que prevalece uma dimensão subjetiva neste processo e, portanto, ocorrem diferenças significativas no estabelecimento das relações, presumivelmente devido às características das deficiências e de seu convívio social, cultural e familiar, bem como da própria cultura escolar.

Cumpre destacar, ainda, a necessidade de se atribuir maior atenção aos processos de interação. Isto aconteceria a partir de uma descrição mais efetiva das relações estabelecidas entre as crianças nos diferentes espaços e momentos do projeto pedagógico. Para tanto, o apoio em elementos da etologia (LORENZ, 1995) poderia contribuir de forma significativa nessas observações.

\section{Considerações finais}

A partir da análise dos dados, é possível identificar o status sociométrico dos alunos com deficiência, estabelecido pela convivência em sala de aula.

Tanto na Educação Infantil como no início do Ensino Fundamental, a natureza da deficiência e as dificuldades de aprendizagem não parecem ser determinantes no processo de inclusão social das crianças. Todavia, os resultados deste estudo remetem ao comportamento e, sobretudo, ao tempo de convivência entre elas.

Sugere-se que outros estudos devem atentar mais à natureza da deficiência e ao grau de dificuldade das crianças, uma vez que isso pode contribuir para o estabelecimento de interações sociais e de inclusão no ambiente escolar, principalmente em anos mais avançados do Ensino Fundamental. É necessário, também, que futuros trabalhos busquem investigar o papel exercido pelos espaços e pelas propostas pedagógicas no processo de interação das crianças, sobretudo, ancorados numa visão mais sistêmica e abrangente do processo de inclusão. Assim, entende-se que seja fundamental a existência de uma preocupação com espaços que possam, eventualmente, proporcionar interação entre as crianças, bem como com a natureza, em tempos destinados a esta aproximação. A 
concepção sistêmica associada à inclusão é fundamental, uma vez que ela pressupõe uma indissociabilidade entre espaços, práticas pedagógicas, interações e aprendizagem.

Finalmente, entende-se a necessidade de investigar esse tema a partir de uma perspectiva longitudinal, acompanhando os grupos ao longo dos diferentes níveis da Educação Básica, ou mesmo a partir dos possíveis desdobramentos de propostas pedagógicas desenvolvidas pelas escolas. Tal fato pode acontecer de forma complementar, a partir de uma metodologia que descreva os processos de interação social estabelecidos de forma mais efetiva.

\section{Referências}

ALMEIDA, Aline Castro. Ensino Fundamental de nove anos: alfabetização e letramento com crianças de seis anos. 2012. 102 f. Dissertação (Mestrado) - Curso de Mestrado em Educação, Educação, Universidade Federal São João del Rei, São João del Rei, 2012.

ALVES, Danny José. O teste sociométrico: sociogramas. Porto Alegre: Editora Globo, 1972.p.128.

ANHÃO, Patrícia Páfaro Gomes; PFEIFER, Luzia lara; SANTOS, Jair Lício dos. Interação social de crianças com síndrome de Down na Educação Infantil. Revista Brasileira de Educação Especial, Marília, v. 16, n. 1, p.31-46, jan. 2010.

\section{AMERICAN PSYCHIATRIC ASSOCIATION. Diagnostic and Statistical Manual of Mental Disorder DSM-V. Draft, 2018.}

BAGAROLLO, Maria Fernanda; RIBEIRO, Vanessa Veis; PANHOCA, Ivone. Anautisticchild's play fromthe cultural-historical perspective. Revista Brasileira de Educação Especial, v. 19, n. 1, p. 107-120, 2013.

BARBOSA, Maria Carmen Silveira. Culturas escolares, culturas de infância e culturas familiares: as socializações e a escolarização no entretecer destas culturas. Rev.

Educação e Sociedade, vol. 28, n 100, 2007, p.1059-1083.

BATISTA, Marcus Welby; ENUMO, Sônia Regina Fiorim. Inclusão escolar e deficiência mental: análise da interação social entre companheiros. Estudos em Psicologia. v. 9, n. 1, p.101-111, abr. 2004.

BAYDIK, Berrin; BAKKALOĞLU, Hatice. Predictors of Sociometric Status for Low Socioeconomic Status Elementary Mainstreamed Students with and without Special Needs. Educational Sciences: Theory \& Practice. v.9 n.2, Spring, p. 435-447, 2009.

BEIERS, Kevin; DERBY, K. Mark; MCLAUGHLIN, T. F. Increasing social interactions using prompts and rewards for adolescents with ASD in an ice hockey practice context. Educational Research Quarterly, v. 39, n. 3, p. 40, 2016. Disponível em: https://search.proquest.com/openview/f37b204c2af84b0bffa958129d7e643e/1 ?pq- 
origsite $=$ gscholar $\& \mathrm{cbl}=48020$ Acesso em: 19/02/2018.

BOCK, Marjorie. The impact of social behavioral strategy training on the social interaction skills of four students with Asperger Syndrome. Focus on Autism and Other Developmental Disabilities. v.4, n.2. p. 45-57, 2007.

https://doi.org/10.1177/10883576070220020901

CAMARGO, Síglia Pimentel Höher; BOSA, Cleonice Alves. Competência social, inclusão escolar e autismo: revisão crítica da literatura. Revista Psicologia \& Sociedade; vol.21, n.1, 2009. P. 65-74.

CAMARGO, Síglia Pimentel Höher et al. Behaviorally based interventions for teaching social interaction skills to children with ASD in inclusive settings: a meta-analysis. Journal of Behavioral Education, v. 25, n. 2, p. 223-248, 2016. Disponível em:

https://link.springer.com/article/10.1007/s10864-015-9240-1. Acesso em: 16/02/2018.

CÉSAR, Margarida; SANTOS, Nuno. From exclusion to inclusion: Collaborative work contributions to more inclusive learning settings. European Journal of Psychology of Education, v. 21, n. 3, p. 333, 2006. Disponível em: https://link.springer.com/article/10.1007/BF03173420. Acesso em: 16/02/2018.

CLEGG, Jennifer; MURPHY, Elizabeth; ALMACK, Kathryn; HARVEY, Anna. Tensions around inclusion: Reframing the moral horizon. Journal of Applied Research in Intellectual Disabilities, v. 21, n. 1, p. 81-94, 2008. Disponível em:

https://onlinelibrary.wiley.com/doi/full/10.1111/j.1468-3148.2007.00371.x Acesso em: 16/02/2018.

CUCKLE, Pat; WILSON, June. Social relationships and friendships among young people with Down's syndrome in secondary schools. British Journal of Special Education, v. 29, n. 2, p. 66-71, 2002. Disponível em:

https://onlinelibrary.wiley.com/doi/abs/10.1111/1467-8527.00242. Acesso em: 19/02/2018.

DALBOSCO, Claudio Almir. Formas de reconhecimento e força intersubjetiva de grupo. Educação e Sociedade, Campinas, v. 36, №. 131, p. 325-341, abr.-jun., 2015. Disponível em: http://dx.doi.org/10.1590/ES0101-73302015137308. Acesso em: 04/12/2019.

EDLER DE CARVALHO, Rosita. Panorama Internacional da Integração: enfoque nacional. Revista Integração, v.12, n. 3, 1991, p.9-13.

FERREIRA, Elizângela Fernandes; MUNSTER, Mey de Abreu van. Avaliação das Habilidades Sociais de Crianças com Deficiência Intelectual sob a Perspectiva dos Professores. Revista Brasileira de Educação Especial, v. 23, n. 1, p. 97-110, 2017.

GIMENEZ, Roberto. A inclusão de crianças com dificuldades motoras nas aulas de educação física: o que fazer com o último a ser escolhido no time? In: GIMENEZ, Roberto\& FREITAS, Alessandro (orgs). Educação física inclusiva na Educação Básica: reflexões, propostas e ações. Curitiba: CRV, 2015. p.245-258. 
GIMENEZ, Roberto; ONHA, Amanda Melges. Educação Física Inclusiva: Impactos da Tutoria no Desempenho de Jovens com Deficiência Intelectual num Jogo PréDesportivo. Cadernos de Pesquisa: Pensamento Educacional, v. 11, n. 28, p. 169-188, 2016. Disponível em: http://seer.utp.br/index.php/a/article/view/317. Acessou 19/02/2018.

GOMES, Rosana Carvalho, NUNES, Debora Regina de Paula. Interações comunicativas entre uma professora e um aluno com autismo na escola comum: uma proposta de intervenção. Educação e Pesquisa, v.40, n.1, p.143-161, 2014.

GONÇALVES, Viviane Oliveira; SILVA, Kelly Suêmia Dutra; FERNANDES, Denise Pereira; FERREIRA, Lorena Barbosa. Educação Física adaptada e avaliação: um caminho para o trabalho motor em alunos com deficiência mental. Pensar a Prática, v. 7, n. 2, p. 231-244, 2004.

GREENWAY, Carol. Autism and Asperger syndrome: Strategies to promote prosocial behaviours. Educational Psychology in Practice, v. 16, n. 4, p. 469-486, 2000. Disponível em: https://www.tandfonline.com/doi/abs/10.1080/713666112. Acesso em: 16/02/2018.

GURALNICK, Michael J. Involvement with peers: comparisons between young children with and without Down's syndrome. Journal of Intellectual Disability Research, v. 46, n. 5, p. 379-393, 2002. Disponível em: https://onlinelibrary.wiley.com/doi/full/10.1046/j.13652788.2002.00405.x. Acesso em: 17/02/20018.

HARRIS, Judith Rich. Where Is the Child's Environment? A Group Socialization Theory of Development. Psychological Review, Middletown, New Jersey, v. 102, n. 3, p.458-489, 1995.

HARRIS, Judith Rich. Diga-me com quem anda... Rio de Janeiro: Objetiva 1999.

HOUSTON-WILSON, Cathy, LIEBERMAN, L. Strategies for teaching students with autism in physical education. Journal of Physical Education Recreation and Dance v 24, p. 40-44, 2013. https://doi.org/10.1080/07303084.2003.10609218

ILYAS, Zahida; SHAHED, Sarah. An impact of perceived social support on old age well being mediated by spirituality, self steem and ego integrity.Journal of religion and Health. v.4, n.3, p.1-18, 2020. https://doi.org/10.1007/s10943-019-00969-6

INEP - INSTITUTO NACIONAL DE ESTUDOS E PESQUISAS EDUCACIONAIS ANÍSIO TEIXEIRA. Sinopse da Educação Básica 2012. Brasília. INEP, 2019. Disponível em: http://inep.gov.br/web/guest/sinopses-estatisticas-da-educacao-basica Acesso em: 12/09/2019.

INEP - INSTITUTO NACIONAL DE ESTUDOS E PESQUISAS EDUCACIONAIS ANÍSIO TEIXEIRA. Sinopse da Educação Básica 2018. Brasília. INEP, 2019. Disponível em: http://inep.gov.br/web/guest/sinopses-estatisticas-da-educacao-basica Acesso em: 12/09/2019.

JOHNSON, Hilary; DOUGLAS, Jacinta; BIGBY, Christine; IACONO, Teresa. Social interaction with adults with severe intellectual disability: Having fun and hanging 
out. Journal of Applied Research in Intellectual Disabilities, v. 25, n. 4, p. 329-341, 2012. Disponível em: https://onlinelibrary.wiley.com/doi/full/10.1111/j.1468-

3148.2011.00669.x. Acesso em: 19/02/2018.

KIRKEBY, Inge Mette; GRANGAARD, Sidse. Can we build inclusion? Studies in health technology and informatics, In. PETRIE, Helen; DARZENTAS, J.; WALSH, Tanja (Ed.). Universal Design 2016: Learning from the Past, Designing for the Future: Proceedings of the 3rd International Conference on Universal Design (UD 2016), York, United Kingdom, August 21-24, 2016. IOS Press, 2016. p. 246-255

LACEY, Penny. The role of learning support assistants in the inclusive learning of pupils with severe and profound learning difficulties. Educational Review, v. 53, n. 2, p. 157167, 2001. Disponível em:

https://www.tandfonline.com/doi/abs/10.1080/00131910120055589. Acesso em: $17 / 02 / 2018$.

LEMOS, Emellyne Lima de Medeiros Dias; SALOMÃO, Nádia Maria Ribeiro; AGRIPINORAMOS, Cibele Shírley. Inclusão de crianças autistas: um estudo sobre interações sociais no contexto escolar. Revista Brasileira de Educação Especial, v. 20, n. 1, p. 117-130, 2014.

LOPES, Lene Wilma Rodrigues; MAGALHAES, Celina Maria Colina; MAURO, Patrícia Izar. Interações entre pré-escolares: possibilidades e análises. Psicologia: Ciência e Profissão, v.23, n.4, p.88-97, 2003.

LORENZ, Korand. Os fundamentos da etologia (Tradução de Pedro Melo Cruz e Carlos Alberts). Universidade Estadual Paulista, São Paulo, 1995.

MACKAY, Tommy; KNOTT, Fiona; DUNLOP, Aline-Wendy. Developing social interaction and understanding in individuals with autism spectrum disorder: A groupwork intervention. Journal of Intellectual and Developmental Disability, v. 32, n. 4, p. 279290, 2007. Disponível em:

https://www.tandfonline.com/doi/abs/10.1080/13668250701689280. Acesso em: 17/02/2018.

MAKIDA-DYONISIO, Cristiane. Inclusão escolar: uma análise sobre os contextos sociais e físicos na Educação Infantil e no Ensino Fundamental. 2017. 137p. Dissertação de Mestrado em Educação. Universidade Cidade de São Paulo, São Paulo, 2017.

MAKIDA-DYONISIO, Cristiane; MARTINS, Ida Carneiro; GIMENEZ, Roberto. Inclusão escolar: uma reflexão sobre a transição da Educação Infantil para o Ensino Fundamental. Comunicações, v. 23, n. 2, p. 207-224, 2016. Disponível em: https://www.metodista.br/revistas/revistas-

unimep/index.php/comunicacoes/article/view/2819 . Acesso em: 16/02/2018.

MEYER, Luanna $\mathrm{H}$. The impact of inclusion on children's lives: Multiple outcomes, and friendship in particular. International Journal of Disability, Development and Education, v. 48, n. 1, p. 9-31, 2001. Disponível em:

https://www.tandfonline.com/doi/abs/10.1080/10349120120036288. Acesso em: 19/02/2018. 
MOLINA, Renata Cristina Moreno; DEL PRETTE, Almir. Mudança no status sociométrico negativo de alunos com dificuldades de aprendizagem. Psicologia Escolar e

Educacional, v.11, n.2. p.299-310, 2007.

NEGRINI, Tatiane; COSTA, Leandra Costa da; ORTIZ, Leodi Conceição Meireles; FREITAS, Soraia Napoleão. Acessibilidade na agenda da inclusão social e educacional. Revista Educação Especial, v. 1, n. 1, p. 287 - 297, 2010.

ODOM, Samuel L. Preschool Inclusion: what we Know and where we go from here? TESCE, v.20, n.1, 2000. p.20-27.

OLIVEIRA, Marta Kohl De. Vygotsky: aprendizado e desenvolvimento: um processo sócio-histórico. São Paulo: Scipione, 1997. 112 p.

ORSMOND, Gael I.; KRAUSS, Marty Wyngaarden; SELTZER, Marsha Mailick. Peer relationships and social and recreational activities among adolescents and adults with autism. Journal of autism and developmental disorders, v. 34, n. 3, p. 245-256, 2004.Disponível em:

https://link.springer.com/article/10.1023/B:JADD.0000029547.96610.df. Acesso em: 17/08/2018.

PADILHA, Anna Maria Lunardi; OLIVEIRA, Ivone Martins (Orgs.). Educação para todos: as muitas fases da inclusão escolar. Campinas, São Paulo: Papirus, 2013.

PAWSON, Nicole; RAGHAVAN, Raghu; SMALL, Neil; CRAIG, Sue; SPENCER, Marion. Social inclusion, social networks and ethnicity: the development of the Social Inclusion Interview Schedule for young people with learning disabilities. British Journal of Learning Disabilities, v. 33, n. 1, p. 15-22, 2005. Disponível em: https://onlinelibrary.wiley.com/doi/full/10.1111/j.1468-3156.2004.00270.x. Acesso em: 19/02/2018.

PICHON-RIVIÈRE, Enric. Teoria do vínculo. São Paulo. Ed. Martins Fontes.2000. p.129.

PIJL, Sip Jan; FROSTAD, Per; FLEM, Annlaug. The social position of pupils with special needs in regular schools. Scandinavian Journal of Educational Research. v.52, n.4, p. 387-405, 2008. Disponível em: https://www.rug.nl/research/portal/publications/the-socialposition-of-pupils-with-special-needs-in-regular-schools(96644222-dbd3-478c-b7f6aec06d42bdca)/export.html

QI, Jing; HA, Amy S. Inclusion in Physical Education: A review of literature. International Journal of Disability, Development and Education, v. 59, n. 3, p. 257-281, 2012. Disponível em: https://www.tandfonline.com/doi/abs/10.1080/1034912X.2012.697737 . Acesso em: 19/02/2018.

REIS, Helena Isabel Silva; PEREIRA, Ana Paula da Silva; ALMEIDA, Leandro S. Características e especificidades da comunicação social na perturbação do espectro do autismo. Revista Brasileira de Educação Especial, v. 22, n. 3, p. 325-336, 2016.

RIX, Jonathan; HALL, Kathy; NIND, Melanie; SHEEHY, Kieron; WEARMOUTH, Janice. 
What pedagogical approaches can effectively include children with special educational needs in mainstream classrooms? A systematic literature review. Support for learning, $v$. 24, n. 2, p. 86-94, 2009. Disponível em:

https://onlinelibrary.wiley.com/doi/full/10.1111/j.1467-9604.2009.01404.x . Acesso em: $12 / 02 / 2018$.

RHEAMS, Theresa Arceneaux; BAIN, Sherry K. Social interaction interventions in an inclusive era: Attitudes of teachers in early childhood self-contained and inclusive settings. Psychology in the Schools, v. 42, n. 1, p. 53-63, 2005. Disponível em: https://onlinelibrary.wiley.com/doi/abs/10.1002/pits.20029. Acesso em: 16/02/2011.

SÁ, Maria das Graças Carvalho Silva de; SIQUARA, Zelinda Orlandi; CHICON, José Francisco. Representação simbólica e linguagem de uma criança com autismo no ato de brincar. Revista Brasileira de Ciências do Esporte [online],vol.37, n.4, pp.355-361, 2015. Disponível em http:http://www.scielo.br/scielo.php?pid=S0101- Acesso em: 18/02/2018.

SANDERSON, Patricia. The arts, social inclusion and social class: the case of dance. British Educational Research Journal, v. 34, n. 4, p. 467-490, 2008. Disponível em: https://onlinelibrary.wiley.com/doi/full/10.1080/01411920701609349. Acesso em: 18/02/2018.

SANTOS, Claudielda Nunes da Silva; et al. A CONTRIBUIÇÃO DAS AULAS DE EDUCAÇÃO FÍSICA PARA A INCLUSÃO DO ALUNO COM TEA. Encontro Alagoano de Educação Inclusiva, v.1, n.1, 2017. Disponível em:

http://www.seer.ufal.br/index.php/eaei/article/view/3814 . Acesso em: 04/12/2019.

SANTOS, Fabio Xavier; MARTINS, Ida Carneiro; GIMENEZ, Roberto. O brincar e os contextos físicos escolares: uma reflexão sobre a Educação Infantil no município de São Paulo. Revista Ambiente @educação, v.12, n.1, p.177-191, 2019.

SILVA, T.T.S. (org.) Identidade e Diferença: a perspectiva dos estudos culturais. Petrópolis, RJ: Vozes, 2000.

SOUZA Vera. Recursos alternativos para o desenvolvimento da comunicação. In: NUNES, Leila Regina. (Org.). Favorecendo o desenvolvimento da comunicação em crianças e jovens com necessidades educacionais especiais. Rio de Janeiro: Dunya. 2003. p. 219-233.

STAINBACK, Susan. \& STAINBACK, William. Inclusão: um guia para educadores. Porto Alegre. Artmed. 1999.

TACHIBANA, Yoshiyuki et al. A systematic review and meta-analysis of comprehensive interventions for pre-school children with autism spectrum disorder (ASD). PloSone, v. 12, n. 12, p. e0186502, 2017. Disponível em:

http://journals.plos.org/plosone/article?id=10.1371/journal.pone.0186502 .Acesso em: 16/02/2018. 
TURNER, John C; HOGG, Michael A; OAKES, Penelope J; REICHER, Stephen D; WETHERELL, Margaret S. Rediscovering the social group: A self-categorization theory. BasilBlackwell, 1987.

VYGOTSKY, Lev. A formação social da mente: o desenvolvimento dos processos psicológicos superiores, São Paulo: Martins Fontes, 1994.

WAINMAN, Briony M; WALKER, Sue; BROWNLEE, Joanne M.; BOULTON-LEWIS, Gillian M.; COBB-MOORE, Charlotte; JOHANSSON, Eva; WHITEFORD, Chrystal. Young children's beliefs about including others in their play: Social and moral reasoning about inclusion and exclusion. Australasian Journal of Early Childhood, v. 37, n. 3, p. 137146, 2011. Disponível em: https://eprints.qut.edu.au/45872/2/45872.pdf. Acesso em: 19/02/2018.

WENDELBORG, Christian; KVELLO, Øyvind. Perceived social acceptance and peer intimacy among children with disabilities in regular schools in Norway. Journal of Applied Research in Intellectual Disabilities, v. 23, n. 2, p. 143-153, 2010. Disponível em: https://onlinelibrary. wiley.com/doi/full/10.1111/j.1468-3148.2009.00515.x . Acesso em: $16 / 02 / 2018$.

\section{Notas}

1 Instrumento: cartaz elaborado pelos autores para identificação dos integrantes da pesquisa por meio de fotos do perfil.

\section{Correspondência}

Cristiane Makida Dyonisio - Universidade Cidade de São Paulo - UNICID, Rua Cesário Galero, 448, Tatuapé, São Paulo, São Paulo, Brasil.

CEP: 03071-000

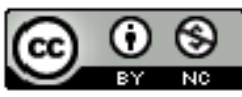

This work is licensed under a Creative Commons Attribution-NonCommercial 4.0 International (CC BY-NC 4.0) 